\title{
Dual U-Slot Loaded Patch Antenna with a Modified L-Probe Feeding
}

\author{
Rakesh N. Tiwari ${ }^{1}$, Prabhakar Singh ${ }^{2}$, Binod Kumar Kanaujia ${ }^{3}$ \\ Department of Electronics and Communication Engineering, Raffles University, Neemrana, Rajasthan, INDIA- \\ 301705, Email: srakeshnath@gmail.com \\ Department of Physics, Galgotias University, Greater Noida, Uttar Pradesh, INDIA-201308 \\ Email: prabhakarsingh3@gmail.com \\ ${ }^{3}$ School of Computational and Integrative Sciences, Jawaharlal Nehru University, New Delhi, INDIA-110067 \\ Email: bkkanaujia@yahoo.co.in
}

\begin{abstract}
In this paper, a modified L-strip fed patch antenna is theoretically analyzed for wideband applications. Dual U-shaped slots are incorporated in the radiating patch and a maximum bandwidth of $16.93 \%(2.65 \mathrm{GHz}$ to $3.14 \mathrm{GHz})$ is achieved. Further, when two parasitic elements are used, antenna bandwidth improves up to $25.89 \%(2.90 \mathrm{GHz}$ to $3.77 \mathrm{GHz})$. The maximum gain of dual $U$-slotted patch and with parasitic elements is $8.23 \mathrm{dBi}$ and $8.46 \mathrm{dBi}$ respectively. Antenna parameters are calculated by CST Microwave studio and equivalent circuit model theory is presented. The proposed antenna is fabricated and the measured results compare well with the theoretical as well as simulated results.
\end{abstract}

Index Terms - Dual U-slot patch antenna; modified L-probe; multilayer patch antenna; gap coupled patch antenna; parasitic elements.

\section{INTRODUCTION}

With the rapid development and attractive solution for various wireless communication systems and demands of their applications, compact and wideband antenna designs have been given immense priority [1], [2]. In this process, various methods were used to improve the bandwidth such as by loading the slots of different size and shape, etching notches and introducing discontinuities in the radiating patch as well as in the ground plane [3], [4]. There are several structures reported to improve the antenna characteristics such as E-shaped [5], [6], C-shaped, U-slot loaded and modified L-strip [7-9]. Different feeding methods also increase the antenna bandwidth such as proximity feed patch, asymmetric CPW fed patch antennas [10], [11]. Substrate with low dielectric constants, multilayer structures and use of air gaps between the dielectric layers increases the impedance bandwidth and gain of the microstrip antennas [12-14]. Besides the fed patch, some parasitic inverted-L wire improves the radiation performance of patch antennas [15], 
[16]. Apart from that some other types of parasitic element design such as slot type, shorted strip type etc [17], [18] can improve the antenna bandwidth and gain.

The present paper reports a radiating structure to study the antenna bandwidth, gain, efficiency and the radiation pattern. Dual U-slot is incorporated in the radiating patch such that one U-slot is lying within another U-slot forming dual U-slot loaded patch antenna (DUSPA). Further, to increase the bandwidth, two parasitic elements are used above this DUSPA. Both designs are fed by modified L-probe. All the calculations are made by using CST Microwave studio. Also, a theoretical analysis for the proposed antenna is developed based on cavity model. The proposed design is fabricated and various antenna parameters are measured. The details of antenna design and results are discussed in the following sections.

\section{ANTENNA DESIGN AND GEOMETRICAL CONFIGURATION}

The top view and the side view of the proposed antenna configuration are shown in Fig. 1. The radiating patch is printed on lower side of a substrate of thickness $h_{2}$. On the other side a conducting strip of dimension $1_{\mathrm{s}} \times \mathrm{w}_{\mathrm{s}}$ is printed. The relative position of the strip is at a distance ' $\mathrm{p}$ ' from the edge of the patch. This strip is excited by center conductor of coaxial probe. The patch is suspended at a height $h_{1}$ from the ground plane. An inverted U-slot of dimensions $L_{2} \times W_{2}$ with width $d_{1}$ is etched within another U-slot of dimensions $L_{1} \times W_{1}$ with same width $d_{1}$. This DUSPA which is printed on the lower side of the substrate of thickness $h_{2}$, is energized by a conducting strip printed on the upper side of this substrate. Further two parasitic elements of dimensions $L_{p} \times W_{p}$ separated by gap $D$ are placed at thickness $h_{3}$ from the conducting strip. These parasitic patches are excited by electromagnetic coupling with DUSPA. A detail design specification is given in Table-1.

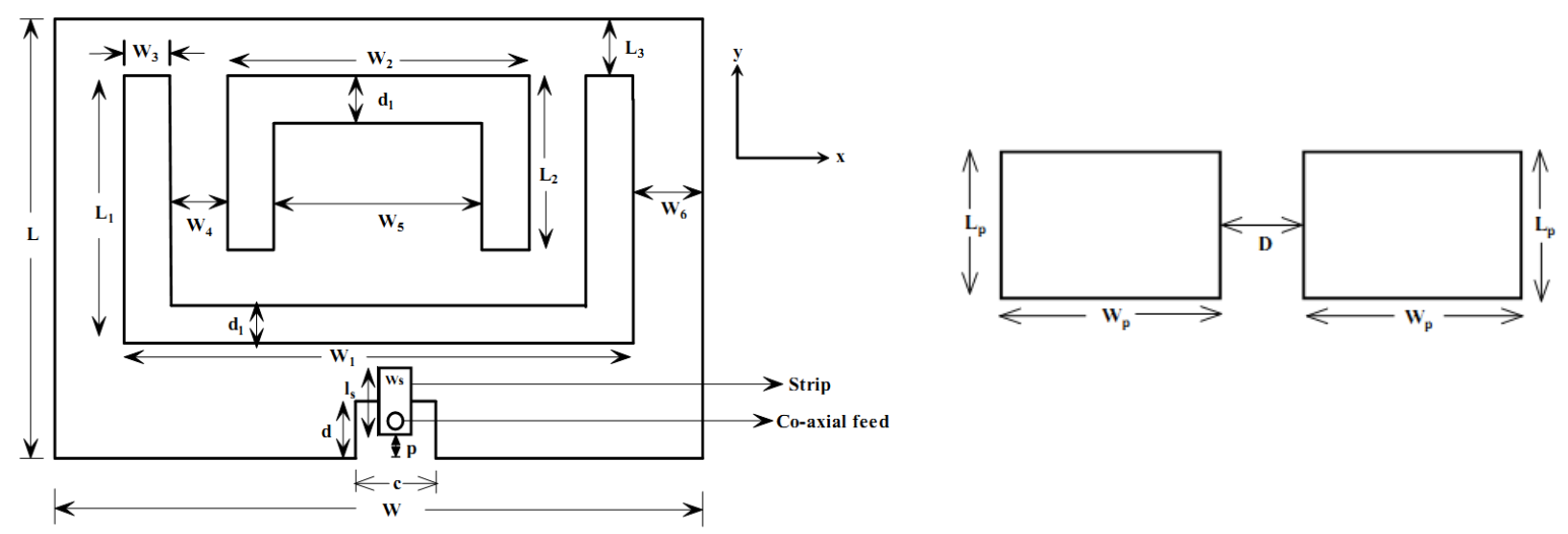

(a) 


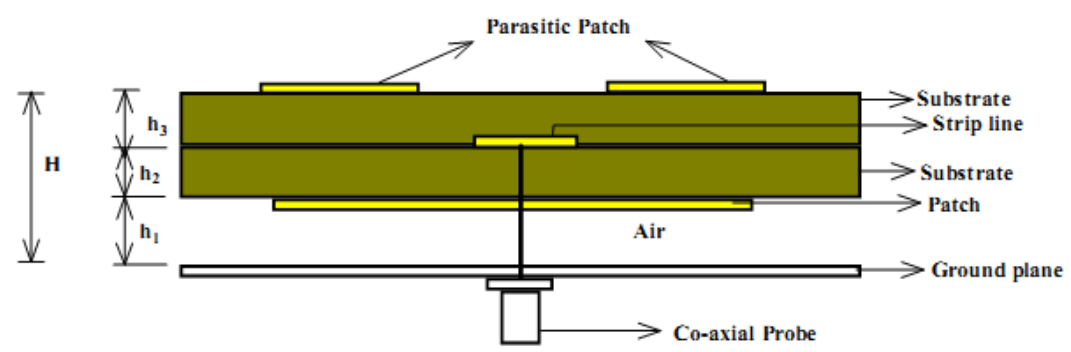

(b)

Fig. 1. Geometry of the proposed antenna (a) Top view (b) Side view.

The proposed antenna is fabricated on Rogers RT duriod substrate (dielectric constant 2.2) with ground plane dimensions $\left(\mathrm{W}_{\mathrm{g}} \times \mathrm{L}_{\mathrm{g}}\right) 80 \times 52 \mathrm{~mm}^{2}$ (Fig. 2).
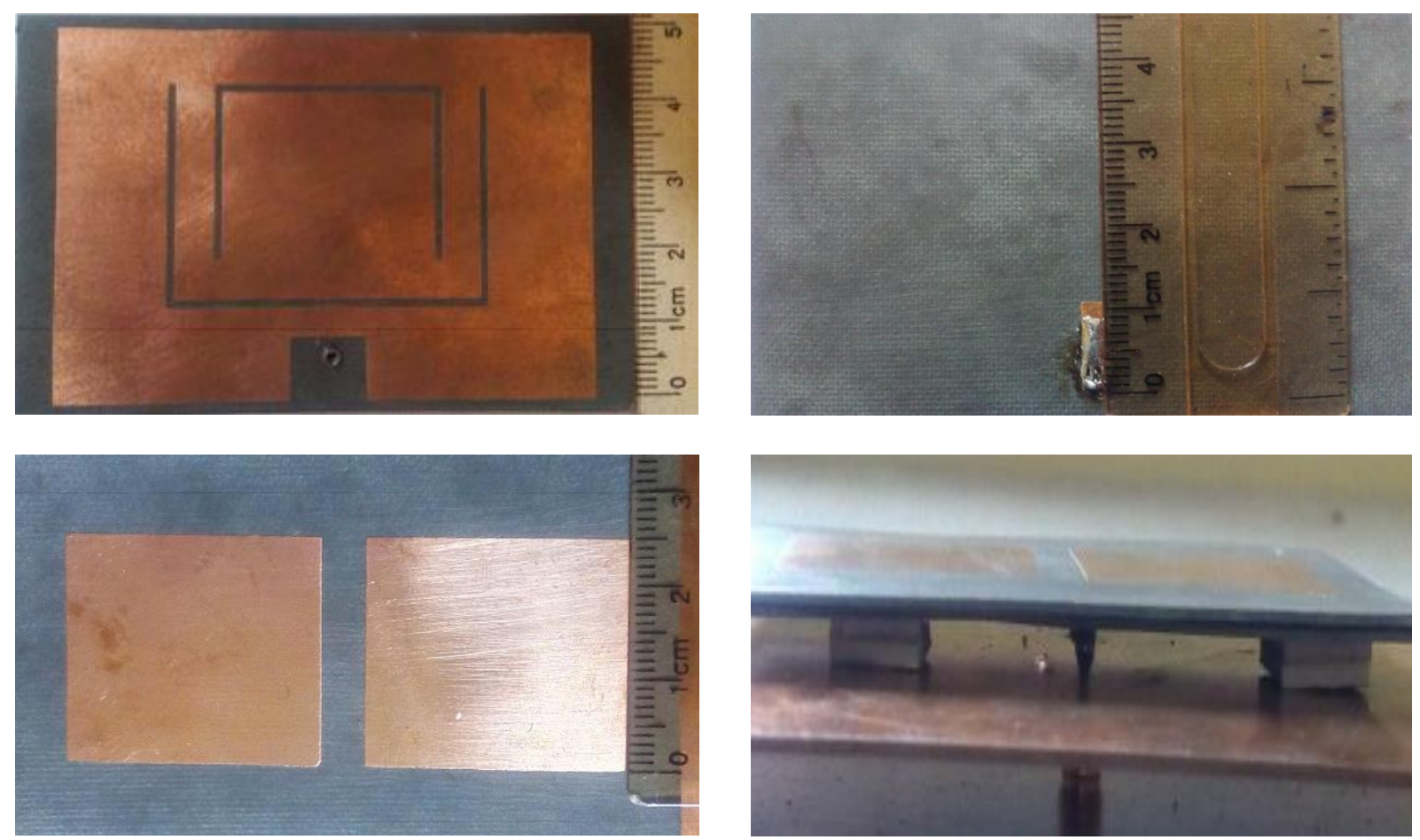

Fig. 2. Photograph of proposed fabricated antenna. 


\section{THEORETICAL INVESTIGATION}

(a) Analysis of modified feeding: Modified L-probe feeding can be analyzed into two parts i.e. vertical probe and horizontal strip.

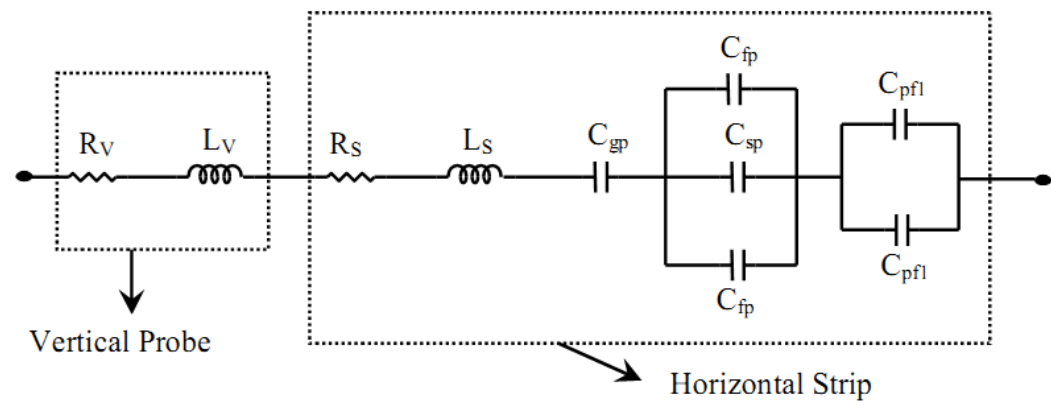

Fig. 3. Equivalent circuit of modified L-probe.

Vertical Probe: Vertical probe can be analyzed as series combination of resistance $R_{v}$ and inductance $L_{v}$, and can be given as [19].

$$
\mathrm{R}_{\mathrm{V}}=\frac{\sqrt{\frac{\sqrt{\mathrm{f \mu}}}{\sigma}}}{\mathrm{d}_{\mathrm{p}}}\left(\mathrm{h}_{1}+\mathrm{h}_{2}\right)
$$

where $\mu=$ permeability of the probe conductor, $f=$ frequency in $\mathrm{GHz}, \mathrm{d}_{\mathrm{p}}=$ diameter of probe

and

$$
\mathrm{L}_{\mathrm{V}}=2.032\left(\mathrm{~h}_{1}+\mathrm{h}_{2}\right)\left[\ln \frac{\left(\mathrm{h}_{1}+\mathrm{h}_{2}\right)}{\mathrm{d}_{\mathrm{p}}}+0.2235 \frac{\mathrm{d}_{\mathrm{p}}}{\left(\mathrm{h}_{1}+\mathrm{h}_{2}\right)}+1.193\right] \mathrm{nH}
$$

Horizontal Strip: A series combination of distributive resistance $\mathrm{R}_{\mathrm{s}}$ and inductive $\mathrm{L}_{\mathrm{s}}$ is developed due to horizontal conducting strip and can be given as [20].

$$
\begin{aligned}
& \mathrm{L}_{\mathrm{S}}=0.2\left(\mathrm{~h}_{1}+\mathrm{h}_{2}\right)\left[\ln \left\{\frac{2\left(\mathrm{~h}_{1}+\mathrm{h}_{2}\right)}{\mathrm{w}_{\mathrm{s}}+\mathrm{t}_{\mathrm{s}}}\right\}+0.2235\left\{\frac{\mathrm{w}_{\mathrm{S}}+\mathrm{t}_{\mathrm{s}}}{\left(\mathrm{h}_{1}+\mathrm{h}_{2}\right)}\right\}+0.5\right] \quad \text { in }(\mathrm{nH}) \\
& \mathrm{R}_{\mathrm{S}}=4.13 \times 10^{-3}\left(\mathrm{~h}_{1}+\mathrm{h}_{2}\right) \frac{\sqrt{\mathrm{f}_{0}}}{\left(\mathrm{w}_{\mathrm{s}}+\mathrm{t}_{\mathrm{s}}\right)} \quad(\mathrm{f} \text { in } \mathrm{GHz})
\end{aligned}
$$

here, $\mathrm{w}_{\mathrm{s}}=$ width of strip, $\mathrm{t}_{\mathrm{s}}=$ thickness of strip, $\rho_{0}=$ ratio of specific resistance of strip and copper.

The distributive capacitance $\mathrm{C}_{\mathrm{sp}}$ between horizontal strip and the radiating patch can be given as

$$
\mathrm{C}_{\mathrm{sp}}=\frac{\varepsilon_{\mathrm{r}} \varepsilon_{0} \mathrm{l}_{\mathrm{s}} \mathrm{w}_{\mathrm{s}}}{\mathrm{h}_{2}}
$$


Since the open ends of the horizontal strip above the radiating patch will have fringing field, so the effective length of the strip is increased. The increment of length will cause some extra capacitance which is fringing capacitance and it can be calculated as

$$
\mathrm{C}_{\mathrm{f}}=\frac{\mathrm{l}_{\mathrm{e}} \varepsilon_{\mathrm{es}}^{-1 / 2}}{\mathrm{cZ_{0 }}}
$$

here,

$$
\mathrm{l}_{\mathrm{e}}=\frac{0.412 \mathrm{~h}\left(\varepsilon_{\mathrm{es}}+0.3\right)\left(\frac{\mathrm{w}_{\mathrm{s}}}{\mathrm{h}}+0.264\right)}{\left(\varepsilon_{\mathrm{es}}-0.258\right)\left(\frac{\mathrm{w}_{\mathrm{s}}}{\mathrm{h}}+0.8\right)}
$$

in which $\varepsilon_{e s}$ is effective dielectric constant for the material under conducting strip [19]. The fringing capacitance $\mathrm{C}_{\mathrm{fp}}$ between open end of the strip and the radiating patch is calculated by putting the substrate height $h=h_{2}$ and the fringing capacitance $C_{f g}$ can be given by putting $h=\left(h_{1}+h_{2}\right)$. The fringing capacitance $C_{p f 1}$ between the parasitic elements and the strip is calculated by putting $h=h_{3}$. The entire feeding acts as a series L-C resonant element and connected in series with the radiating patch. The impedance of this modified L-probe can be calculated using Fig. 3 as

$$
Z_{L S}=R_{v}+j \omega L_{v}+R_{S}+j \omega L_{s}+\frac{1}{j \omega C_{g p}}+\frac{1}{j \omega C_{e q}}
$$

where,

$$
C_{e q}=\frac{2 C_{p f 1}\left(2 C_{f p}+C_{s p}\right)}{2 C_{p f 1}+2 C_{f p}+C_{s p}}
$$

(b) Analysis for DUSPA: The value of capacitance $\mathrm{C}_{1}$, inductance $\mathrm{L}_{1}$ and resistance $\mathrm{R}_{1}$ for a rectangular patch can be given as [20].

$$
\begin{gathered}
\mathrm{C}_{1}=\frac{\varepsilon_{0} \varepsilon_{\mathrm{e}} \mathrm{LW}}{2\left(\mathrm{~h}_{1}+\mathrm{h}_{2}\right)} \cos ^{-2}\left(\frac{\pi \mathrm{l}_{\mathrm{s}}}{\mathrm{W}}\right) \\
\mathrm{L}_{1}=\frac{1}{\omega^{2} \mathrm{C}_{1}} \\
\mathrm{R}_{1}=\frac{\mathrm{Q}_{\mathrm{r}}}{\omega \mathrm{C}_{1}}
\end{gathered}
$$

where, $\mathrm{L}=$ length of the patch, $\mathrm{W}=$ width of the patch, $\mathrm{f}_{1}=$ resonance frequency, $l_{s}=$ feed point location, $\omega=2 \pi f_{1}$ and $\mathrm{Q}_{\mathrm{r}}$ is the quality factor of the resonator. 


$$
\mathrm{Q}_{\mathrm{r}}=\frac{\mathrm{c} \sqrt{\varepsilon_{\mathrm{e}}}}{4 \mathrm{f}_{1}\left(\mathrm{~h}_{1}+\mathrm{h}_{2}\right)}
$$

where, $\mathrm{c}=$ velocity of light, $\mathrm{f}_{1}=$ design frequency, $\varepsilon_{\mathrm{e}}=$ effective permittivity of the medium

$$
\varepsilon_{\mathrm{e}}=\frac{\varepsilon_{\mathrm{rs}}+1}{2}+\frac{\varepsilon_{\mathrm{rs}}-1}{2}\left(1+\frac{10\left(\mathrm{~h}_{1}+\mathrm{h}_{2}\right)}{\mathrm{L}}\right)^{-1 / 2}
$$

in which, $\varepsilon_{\mathrm{rs}}$ can be calculated as

$$
\varepsilon_{\mathrm{rs}}=\frac{\sum_{\mathrm{i}=1}^{\mathrm{n}} \mathrm{h}_{\mathrm{i}}}{\sum_{\mathrm{i}=1}^{\mathrm{n}}\left(\frac{\mathrm{h}_{\mathrm{i}}}{\varepsilon_{\mathrm{ri}}}\right)}
$$

where, $\mathrm{n}$ is the number of stacked layers and $\varepsilon_{\mathrm{r}}=$ relative permittivity of the substrate material.

A slot in the radiating structure can be analyzed using the duality relationship between the dipole and slot [21]. The radiation resistance of an inclined slot in the patch is given by

$$
R_{r}=\frac{\eta_{0} \cos ^{2} \alpha}{2 \pi} \int_{0}^{\pi}\left[\frac{\left[\cos \frac{k^{2} \cos \theta}{2}-\cos \frac{k L_{1}}{2}\right]^{2}}{\sin \theta}\right] d \theta
$$

The input reactance of the inclined slot is given as [22]

$$
\begin{aligned}
& \mathrm{X}_{\mathrm{r}}=30 \cos ^{2} \alpha\left[2 \mathrm{~S}_{\mathrm{i}}\left(\mathrm{kL}_{1}\right)+\cos \left(\mathrm{kL}_{1}\right)\left\{2 \mathrm{~S}_{\mathrm{i}}\left(\mathrm{kL}_{1}\right)-\mathrm{S}_{\mathrm{i}}\left(2 \mathrm{~kL}_{1}\right)-\sin \left(\mathrm{kL}_{1}\right)\right\} \times\left\{2 \mathrm{C}_{\mathrm{i}}\left(\mathrm{kL}_{1}\right)-\mathrm{C}_{\mathrm{i}}\left(2 \mathrm{~kL}_{1}\right)-\right.\right. \\
& \left.\left.\mathrm{C}_{\mathrm{i}}\left(2 \mathrm{~kL}_{1}\right)-\mathrm{C}_{\mathrm{i}}\left(\frac{2 \mathrm{kd}_{1}^{2}}{\mathrm{~L}_{1}}\right)\right\}\right]
\end{aligned}
$$

here, $\alpha$ is the inclination angle of slot with respect to x-axis, $S_{i}$ and $C_{i}$ are the sine and cosine integrals, $d_{1}$ $=$ thickness of the slot, $\mathrm{L}_{1}=$ length of the slot. Impedance for this inclined slot is given by [22]

$$
\mathrm{Z}_{\mathrm{s}}=\frac{\eta_{0}^{2}}{4 \mathrm{Z}}
$$

here

$$
\mathrm{Z}=\mathrm{R}_{\mathrm{r}}\left(\mathrm{kL}_{1}\right)-\mathrm{j}\left[120\left\{\ln \left(\frac{\mathrm{L}_{1}}{\mathrm{~d}_{1}}\right)-1\right\} \cot \left(\frac{\mathrm{kL}_{1}}{2}\right)-\mathrm{X}_{\mathrm{r}}\left(\mathrm{kL}_{1}\right)\right]
$$

Now, U-slot in a patch is analyzed by assuming two slots along the y-axis as the vertical slot of length ' $\mathrm{L}_{1}$ ' at angle $\alpha=0^{\circ}$ and a slot along $\mathrm{x}$-axis as the horizontal slot of dimension ' $\mathrm{W}_{1}$ ' at angle $\alpha=90^{\circ}$. 
The input impedance of the vertical slot can be calculated by using equations (9), (10) and (11) as:

$$
\mathrm{Z}_{\mathrm{V}}=\frac{\eta_{0}^{2}}{4 \mathrm{Z}_{\mathrm{V} 1}}
$$

here, $\mathrm{Z}_{\mathrm{V} 1}$ is calculated by putting $\alpha=0^{0}$. Similarly the impedance of the horizontal slot can be calculated as:

$$
\mathrm{Z}_{\mathrm{H}}=\frac{\eta_{0}^{2}}{4 \mathrm{Z}_{\mathrm{H} 1}}
$$

here, $\mathrm{Z}_{\mathrm{H} 1}$ is calculated by putting $\alpha=90^{\circ}$. Thus equivalent circuit for $\mathrm{U}$-slot in the patch is given by Fig. 4.

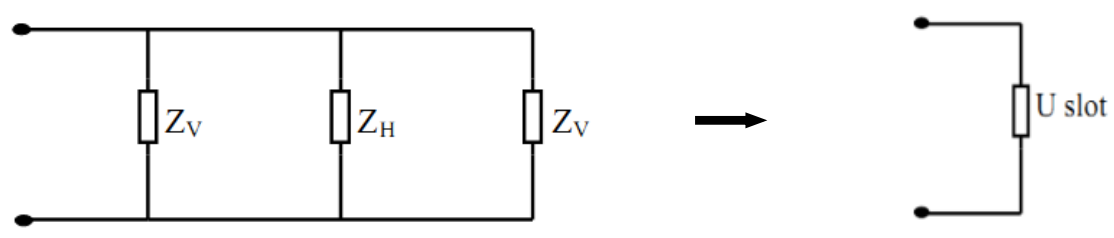

Fig. 4. Equivalent circuit of U-slot in the patch.

Thus, the equivalent circuit for modified L-probe fed patch can be given as shown in Fig. 5.

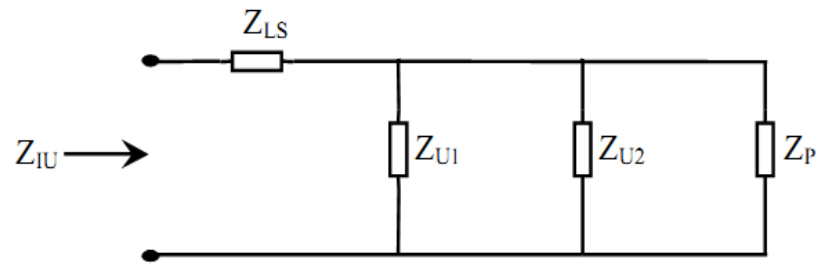

Fig. 5. Equivalent circuit of DUSPA.

The input impedance of DUSPA is calculated by using Fig. 5 as:

$$
\mathrm{Z}_{\mathrm{IU}}=\mathrm{Z}_{\mathrm{LS}}+\frac{1}{\frac{1}{\mathrm{z}_{\mathrm{U} 1}+\frac{1}{\mathrm{Z}_{\mathrm{U} 2}}+\frac{1}{\mathrm{Z}_{\mathrm{P}}}}}
$$

in which, $\mathrm{Z}_{\mathrm{U} 1}$ and $\mathrm{Z}_{\mathrm{U} 2}$ are the impedances of two $\mathrm{U}$-slots in the patch and can be calculated using Fig. 4 and $\mathrm{Z}_{\mathrm{P}}$ is the impedance of the rectangular patch and can be calculated as:

$$
\mathrm{Z}_{\mathrm{P}}=\frac{1}{\frac{1}{\mathrm{R}_{1}}+\frac{1}{\mathrm{j} \omega \mathrm{L}_{1}}+\mathrm{j} \omega \mathrm{C}_{1}}
$$


(c) Analysis of the parasitic elements: The parasitic elements are excited through the electromagnetic coupling with DUSPA. Each parasitic element is considered equivalent to parallel combination of resistance $\mathrm{R}_{\mathrm{p}}, \mathrm{L}_{\mathrm{p}}$ and $\mathrm{C}_{\mathrm{p}}$. These two parasitic elements are coupled with each other by the gap coupling and the equivalent circuit is given in Fig. 6. The equivalent circuit of the gap can be given as a $\pi$-circuit, consisting of the gap coupling capacitance $\mathrm{C}_{\mathrm{g}}$ and the plate capacitances $\mathrm{C}_{\mathrm{P} 1}$. Now two radiating structures (DUSPA and parasitic elements) are coupled through the electromagnetic coupling.

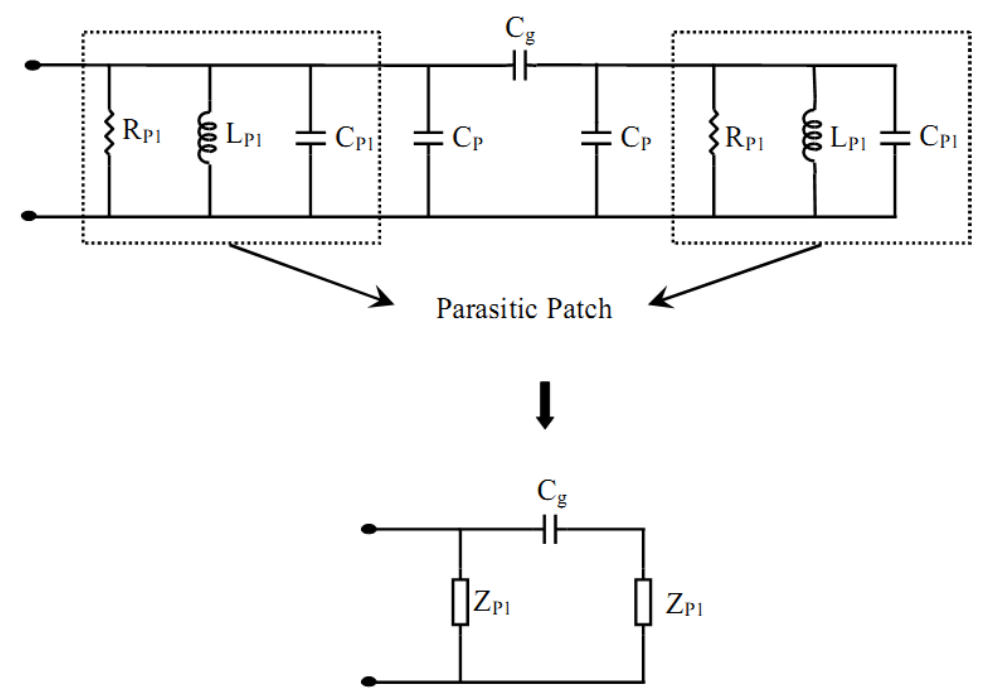

Fig. 6. Equivalent circuit for the gap coupled parasitic elements.

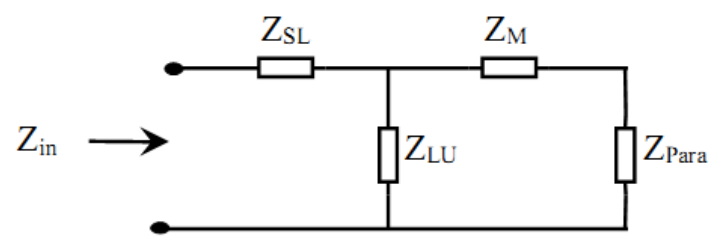

Fig. 7. Equivalent circuit of the modified L-probe fed DUSPA with parasitic elements.

The accurate equations for the coupling capacitance $C_{g}$ and the plate capacitances $C_{P 1}$ of the microstrip gap can be calculated from the hybrid mode analysis [23], [24]. Now using the equivalent circuit as shown in Fig. 7, the total input impedance of DUSPA with parasitic elements can be calculated as:

$$
Z_{\text {in }}=Z_{S L}+\frac{Z_{L U} \times\left(Z_{M}+Z_{\text {Para }}\right)}{Z_{L U}+Z_{M}+Z_{\text {Para }}}
$$

and

$$
\begin{gathered}
Z_{M}=2\left(\frac{1-\omega^{2} L_{M} C_{M}}{j \omega C_{M}}\right) \\
Z_{\text {Para }}=\frac{Z_{P 1} \times Z_{g}}{Z_{P 1}+Z_{g}}
\end{gathered}
$$

in which, 


$$
\mathrm{Z}_{\mathrm{g}}=\mathrm{Z}_{\mathrm{P} 1}+\frac{1}{\mathrm{j} \omega \mathrm{C}_{\mathrm{g}}}
$$

here, $\mathrm{L}_{\mathrm{M}}, \mathrm{C}_{\mathrm{M}}$ are the mutual coupling inductance and capacitance between two radiators and $\mathrm{Z}_{\mathrm{P} 1}$ is the impedance of parasitic elements.

Using equation (16), we can calculate the reflection coefficient, VSWR and return loss of the proposed antennas.

$$
\text { Reflection Coefficient, } \Gamma=\left|\frac{\mathrm{z}_{\mathrm{in}}-\mathrm{Z}_{0}}{\mathrm{Z}_{\mathrm{in}}+\mathrm{Z}_{0}}\right|
$$

where, $\mathrm{Z}_{0}=$ characteristic impedance of the coaxial feed $(50 \Omega)$

$$
\operatorname{VSWR}=\frac{1+|\Gamma|}{1-|\Gamma|}
$$

and

$$
\text { Return loss }=-20 \log _{10}(\Gamma)
$$

Table 1. Design specifications of the proposed antenna:

\begin{tabular}{|l|l|}
\hline Parameter & Value \\
\hline $\mathrm{W}_{\mathrm{g}} \times \mathrm{L}_{\mathrm{g}}$ & $80 \times 52 \mathrm{~mm}^{2}$ \\
\hline $\mathrm{W} \times \mathrm{L}$ & $70 \times 48 \mathrm{~mm}^{2}$ \\
\hline $\mathrm{W}_{1} \times \mathrm{L}_{1}$ & $42 \times 29 \mathrm{~mm}^{2}$ \\
\hline $\mathrm{W}_{2} \times \mathrm{L}_{2}$ & $30 \times 23 \mathrm{~mm}^{2}$ \\
\hline $\mathrm{c} \times \mathrm{d}$ & $10 \times 8 \mathrm{~mm}^{2}$ \\
\hline Air gap $\left(\mathrm{h}_{1}\right)$ & $3.5 \mathrm{~mm}$ \\
\hline Height of dielectric substrate $\left(\mathrm{h}_{2}\right)$ & $1.55 \mathrm{~mm}$ \\
\hline Height of dielectric substrate $\left(\mathrm{h}_{3}\right)$ & $1.50 \mathrm{~mm}$ \\
\hline Substrate used & $\mathrm{RT} / \mathrm{duriod} 5880\left(\varepsilon_{\mathrm{r}}=2.2\right)$ \\
\hline Conducting strip $\left(\mathrm{W}_{\mathrm{s}} \times \mathrm{l}_{\mathrm{s}}\right)$ & $3.0 \times 10.5 \mathrm{~mm}^{2}$ \\
\hline $\mathrm{W}_{\mathrm{p}} \times \mathrm{L}_{\mathrm{p}}$ & $31.2 \times 25 \mathrm{~mm}^{2}$ \\
\hline $\mathrm{d}_{1}$ & $1.0 \mathrm{~mm}$ \\
\hline $\mathrm{W}_{3}$ & $5.0 \mathrm{~mm}$ \\
\hline $\mathrm{W}_{4}$ & $28.0 \mathrm{~mm}$ \\
\hline $\mathrm{W}_{5}$ & $14.0 \mathrm{~mm}$ \\
\hline $\mathrm{D}$ & $5.6 \mathrm{~mm}$ \\
\hline $\mathrm{H}$ & $6.85 \mathrm{~mm}$ \\
\hline $\mathrm{l}_{3}$ & $7.0 \mathrm{~mm}$ \\
\hline $\mathrm{p}$ & $5.0 \mathrm{~mm}$ \\
\hline
\end{tabular}




\section{RESULT AND DISCUSSION}

Fig. 8 shows the simulated return loss obtained from CST Microwave studio for different values of dual U-slot width $\left(d_{1}\right)$. From the graph it is observed that entire operating band shifts towards higher side for increasing value of $d_{1}$, however, antenna bandwidth decreases with increasing value of $d_{1}$. The bandwidth of the antenna is calculated for return loss $<-10 \mathrm{~dB}$ and found maximum $(16.67 \%, 2.66-3.14 \mathrm{GHz})$ at $\mathrm{d}_{1}$ $=1.0 \mathrm{~mm}$ and below $\mathrm{d}_{1}=1.0 \mathrm{~mm}$ the antenna exhibits dual band nature.

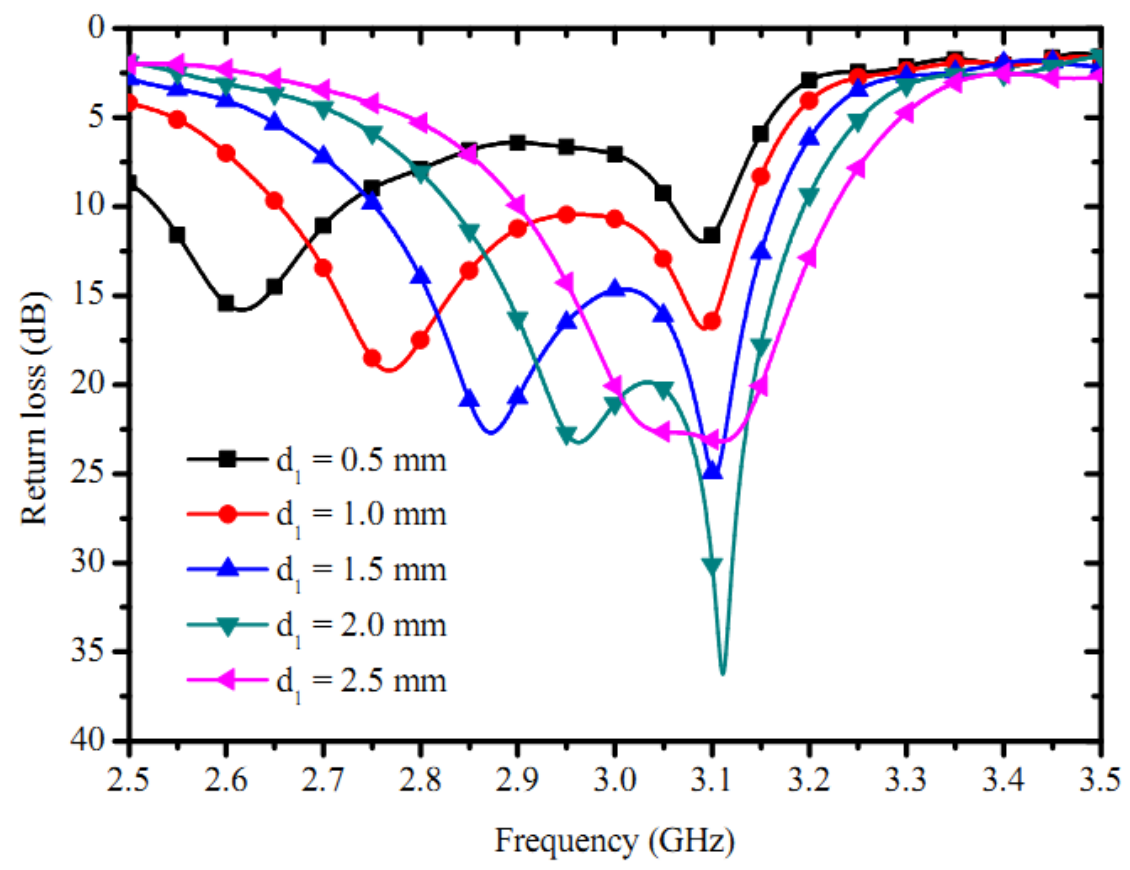

Fig. 8. Variation of return loss with frequency for different slot thickness $\left(\mathrm{d}_{1}\right)$.

A comprehensive analysis has been done to study the bandwidth variation of DUSPA for different combination of dual U-slot length $\mathrm{L}_{1}, \mathrm{~L}_{2}$ and slot width $\mathrm{d}_{1}$. From Fig. 9, it is observed that the bandwidth of the antenna increases with increasing value of slot length $\mathrm{L}_{1}$. The maximum bandwidth $(16.67 \%)$ is obtained at $\mathrm{d}_{1}=1.0 \mathrm{~mm}$ and $\mathrm{L}_{1}=30.0 \mathrm{~mm}$. Fig. 10 reveals the similar variation of bandwidth as observed in Fig. 9. The highest bandwidth $(16.93 \%, 2.65$ to $3.14 \mathrm{GHz})$ is seen when $\mathrm{d}_{1}=1.0 \mathrm{~mm}, \mathrm{~L}_{1}=30.0 \mathrm{~mm}$ and $\mathrm{L}_{2}=24.0 \mathrm{~mm}$. 


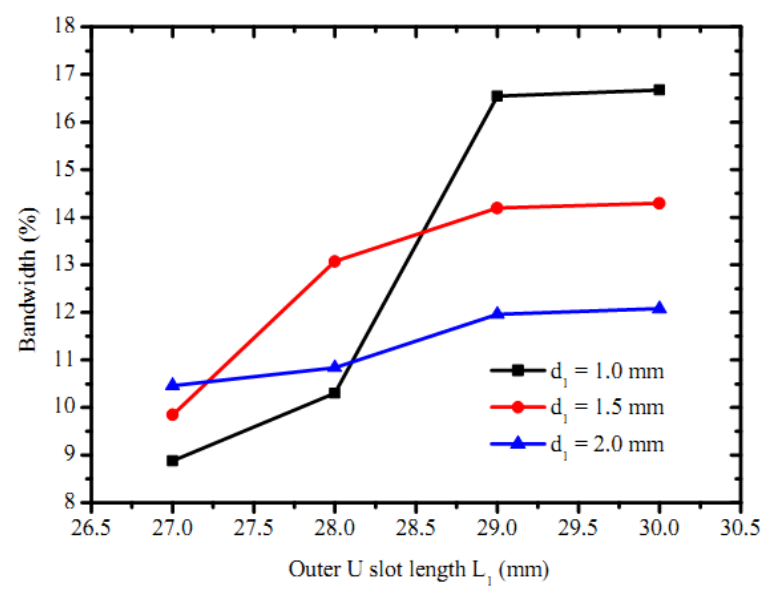

(a)

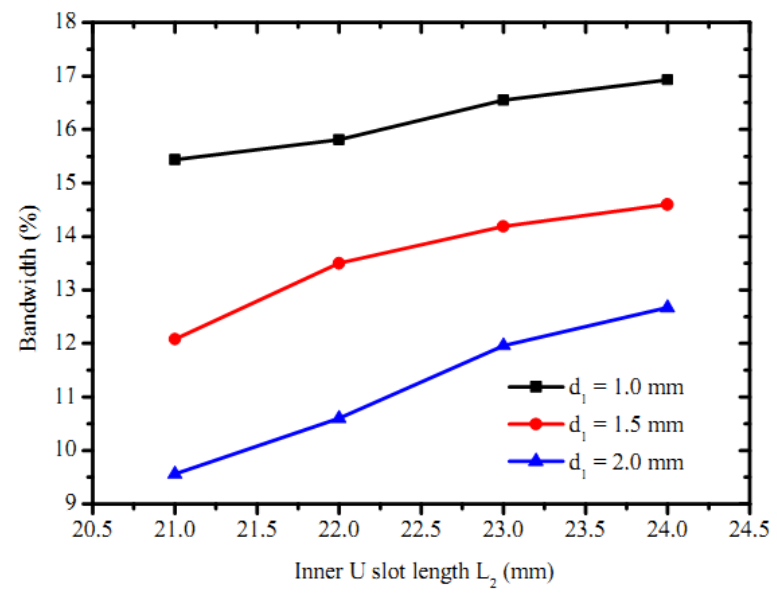

(b)

Fig. 9. Bandwidth variation of DUSPA for different (a) outer slot length $L_{1}$ (b) inner slot length $L_{2}$.

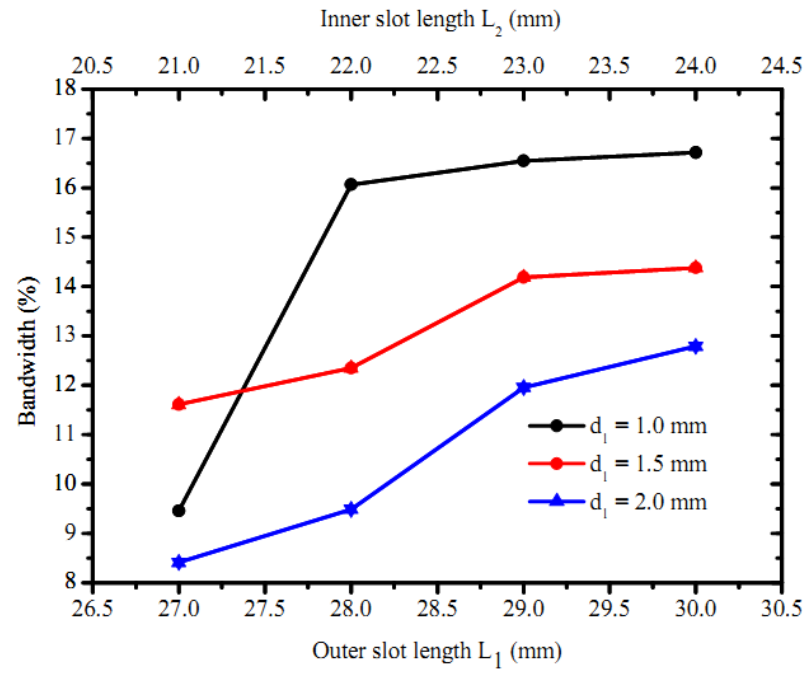

Fig. 10. Bandwidth variation of DUSPA for combination of $\mathrm{L}_{1}$ and $\mathrm{L}_{2}$.

In the process of improving the antenna bandwidth, two parasitic elements are placed at a distance 3.05 $\mathrm{mm}$ from DUSPA. Fig. 11 shows the variation of return loss with frequency for different values of parasitic patch length $\left(\mathrm{L}_{\mathrm{p}}\right)$. It is observed that the bandwidth is almost invariant with $\mathrm{L}_{\mathrm{p}}$. The optimum bandwidth achieved is $25.26 \%$ varying from 2.88 to $3.71 \mathrm{GHz}$ at $\mathrm{L}_{\mathrm{p}}=26.0 \mathrm{~mm}$. However, when $\mathrm{L}_{\mathrm{p}}=$ $27.0 \mathrm{~mm}$, the antenna exhibits dual nature. 


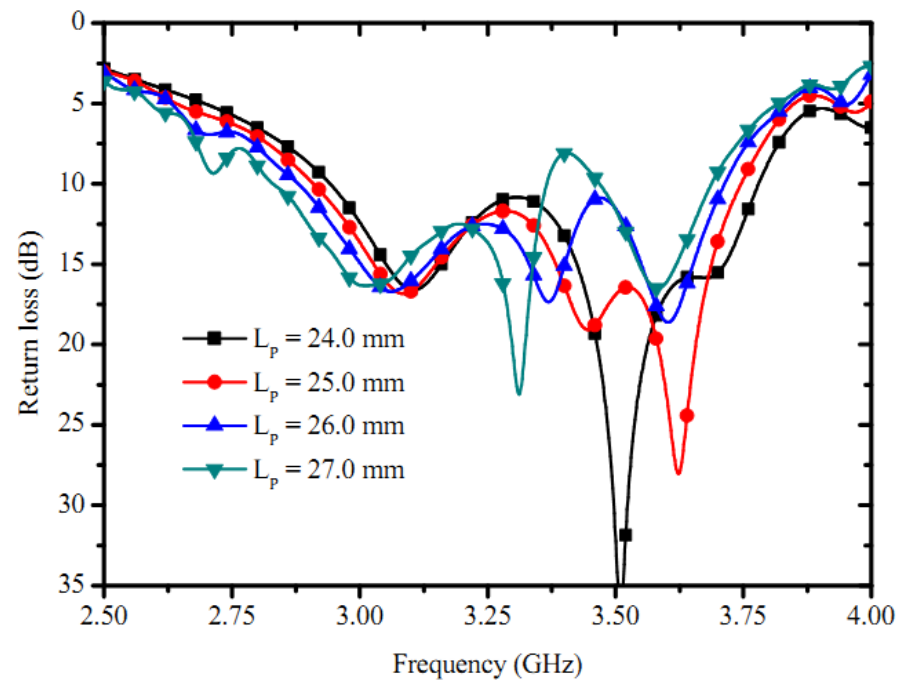

Fig. 11. Variation of return loss with frequency for different values of $\mathrm{L}_{\mathrm{p}}$.

From Fig. 12, it is observed that bandwidth decreases as gap D increases. The maximum bandwidth obtained is $24.59 \%$ (from 2.92 to $3.74 \mathrm{GHz}$ ) at $\mathrm{D}=5.0 \mathrm{~mm}$. At the higher value of $\mathrm{D}$, the gap coupling effect between two parasitic elements is ceases to exist and the antenna starts behaving like DUSPA. Below $\mathrm{D}<5.0 \mathrm{~mm}$ the increment in the bandwidth is almost constant.

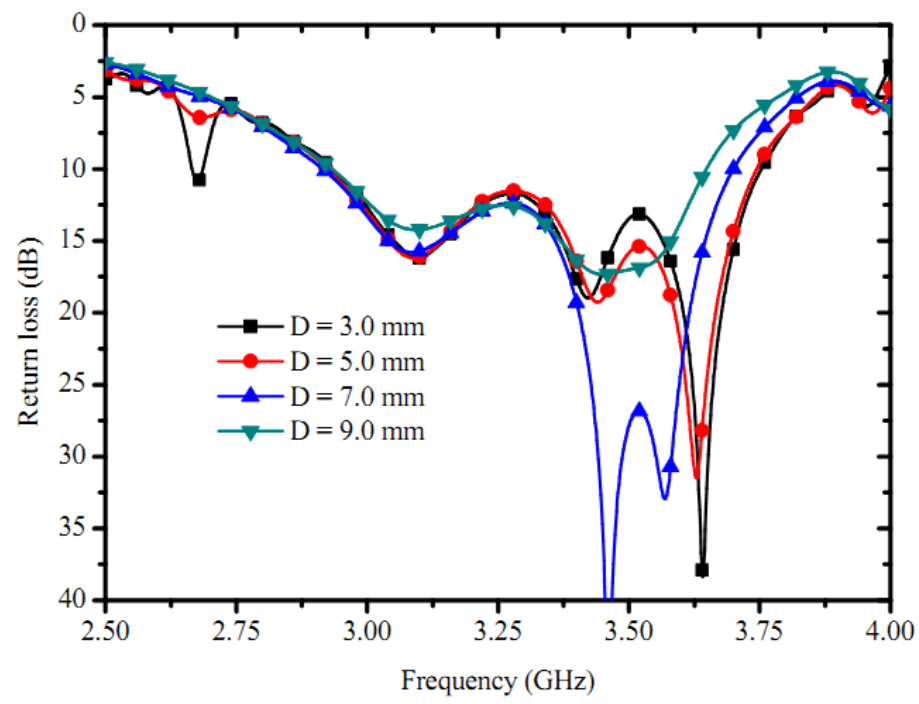

Fig. 12. Variation of return loss with frequency for different value of gap ' $D$ '.

From Fig. 13, it is observed that the bandwidth of the antenna increases with decreasing the value of $\mathrm{W}_{\mathrm{p}}$. From this graph it is observed that the highest operating bandwidth of $25.89 \%$ (from 2.90 to $3.77 \mathrm{GHz}$ ) is achieved for the optimized value of $\mathrm{W}_{\mathrm{p}}=31.2 \mathrm{~mm}$. Further, below $31.2 \mathrm{~mm}$ the antenna shows dual nature. 


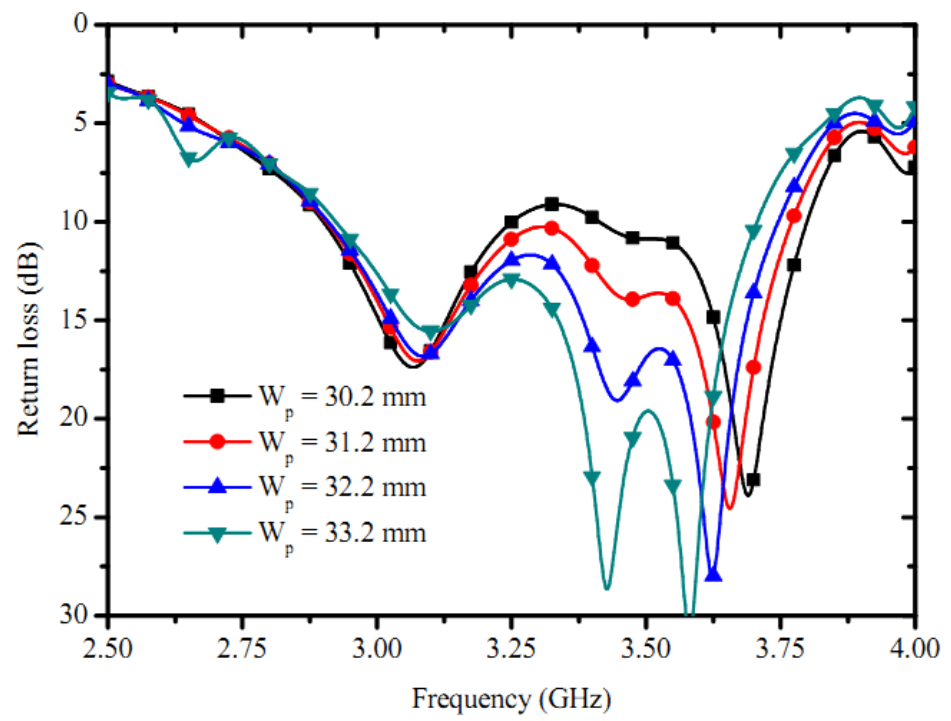

Fig. 13. Variation of return loss with frequency for different values of $\mathrm{W}_{\mathrm{p}}$.

The simulated return loss is compared with the theoretical and the measured results of DUSPA and DUSPA with parasitic elements respectively (Fig. 14). From the graph it is clear that simulated and theoretical results of both the antennas are agreeing quiet well with the measured one. Fig. 15 depicts the simulated and measured gain for both the antennas. The simulated peak gain for DUSPA is $8.23 \mathrm{dBi}$ at $2.8 \mathrm{GHz}$ while for DUSPA with parasitic elements peak gain is $8.46 \mathrm{dBi}$ at $3.0 \mathrm{GHz}$. For DUSPA, the maximum gain variation is $0.63 \mathrm{dBi}$ for the entire band of operation $(2.75-3.10 \mathrm{GHz})$ while for DUSPA with parasitic elements it is $0.96 \mathrm{dBi}$ for the entire band of operation $(2.82-3.75 \mathrm{GHz})$.

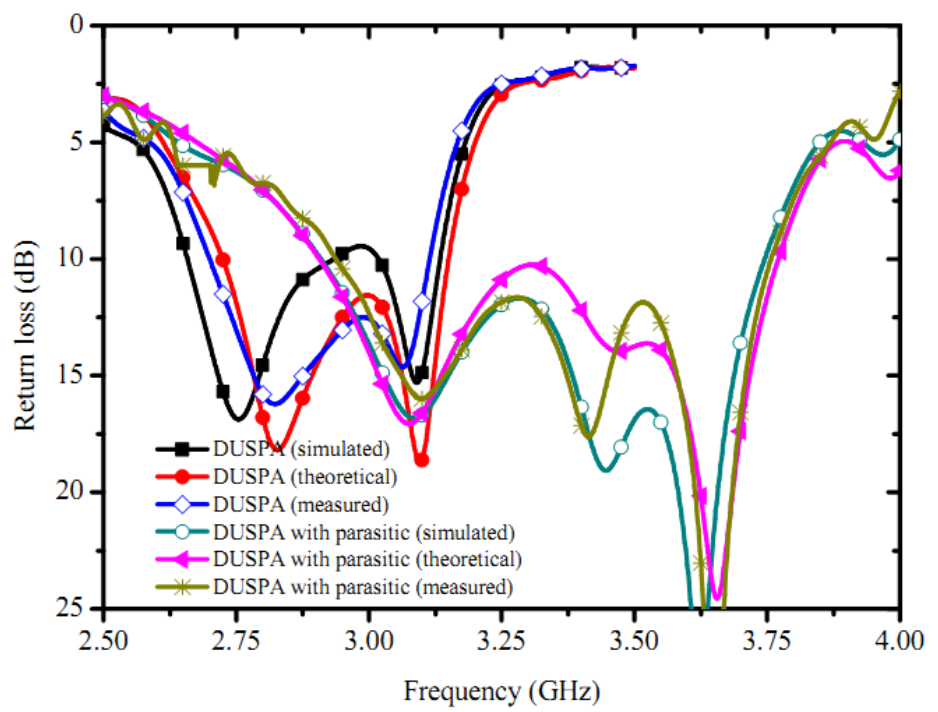

Fig. 14. Measured return loss for DUSPA and DUSPA with parasitic elements. 


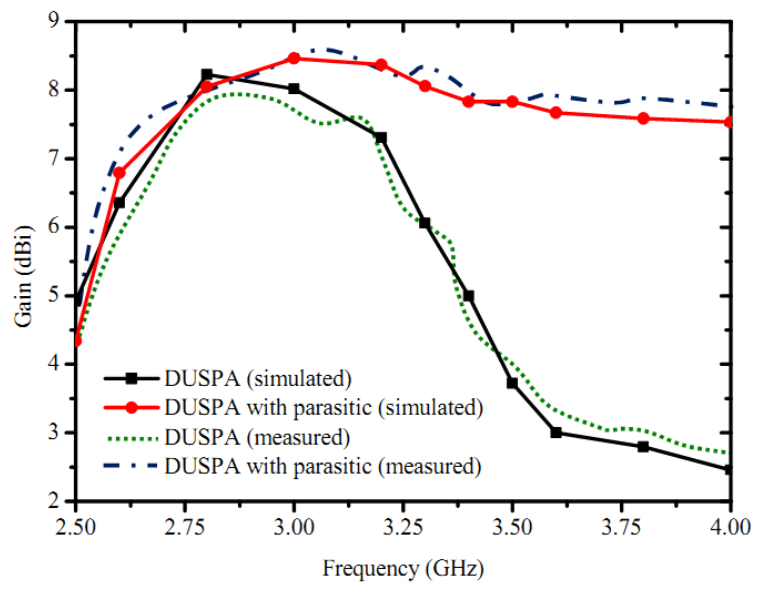

Fig. 15. Measured gain for DUSPA and DUSPA with parasitic elements.

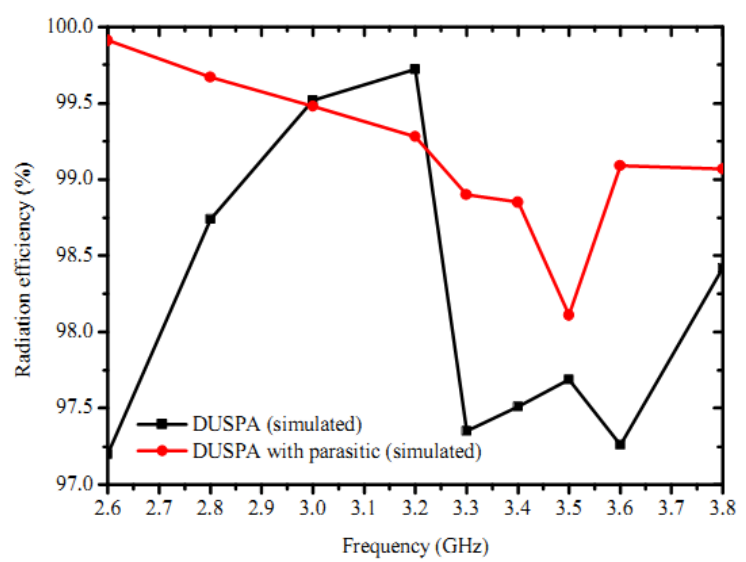

Fig. 16. Simulated radiation efficiency for DUSPA and DUSPA with parasitic elements.

Radiation efficiency is calculated for both the antennas and found quite acceptable (above 97.0\%) for entire operating frequency band (Fig. 16). The radiation patterns of the proposed antennas are measured using anechoic chamber. Fig. 17 shows the measured and simulated radiation patterns for DUSPA at 2.80 $\mathrm{GHz}$ and $3.09 \mathrm{GHz}$. The cross polarization level is quite low at $\varphi=90^{\circ}$ than that at $\varphi=0^{\circ}$. A good agreement between the measured and simulated results is observed. Radiation patterns for DUSPA with parasitic elements are plotted at $3.09 \mathrm{GHz}, 3.45 \mathrm{GHz}$ and $3.63 \mathrm{GHz}$ (Fig. 18). The cross polarization level at $\varphi=90^{\circ}$ is again quite low than that at $\varphi=0^{\circ}$ for all three resonant frequencies. This is primarily because of the feed location which is along y-axis. Also, the inherent asymmetry property of probe feed which generates higher order modes and hence increases the cross-polarization level. In the measured results, some ripples are observed below ground plane due to reflection of radiation by the conducting strip. The simulated radiation pattern is compared with measured results however, some mismatch is observed in radiation pattern due to fabrication inaccuracy and numerical methods used in simulator. 
It is observed that all simulated co-polar graphs are showing almost semi circular back lobe bellow the ground plane. It may be due to the size and thickness limitation of the ground plane taken in our design for the simulation. Both the antennas exhibit linearly polarized, broadside and symmetrical radiation patterns for entire operating frequency band.
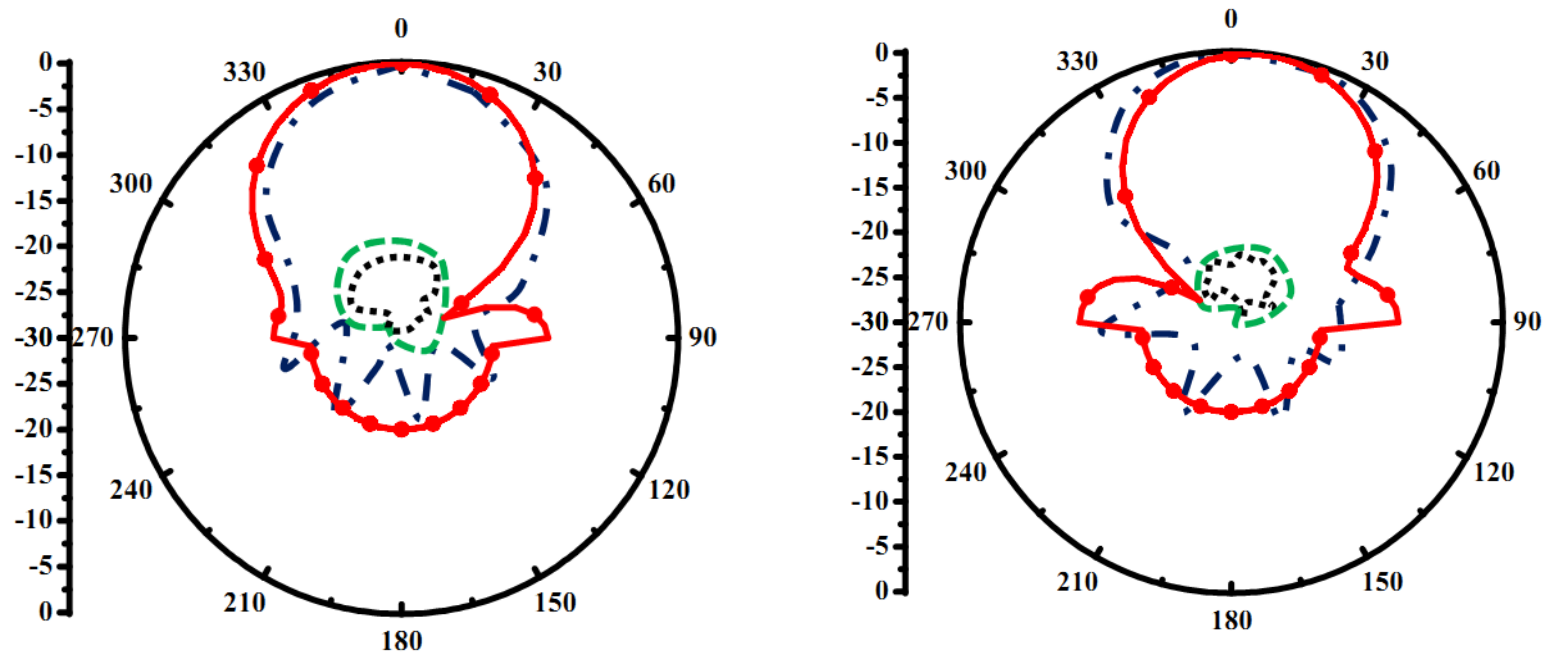

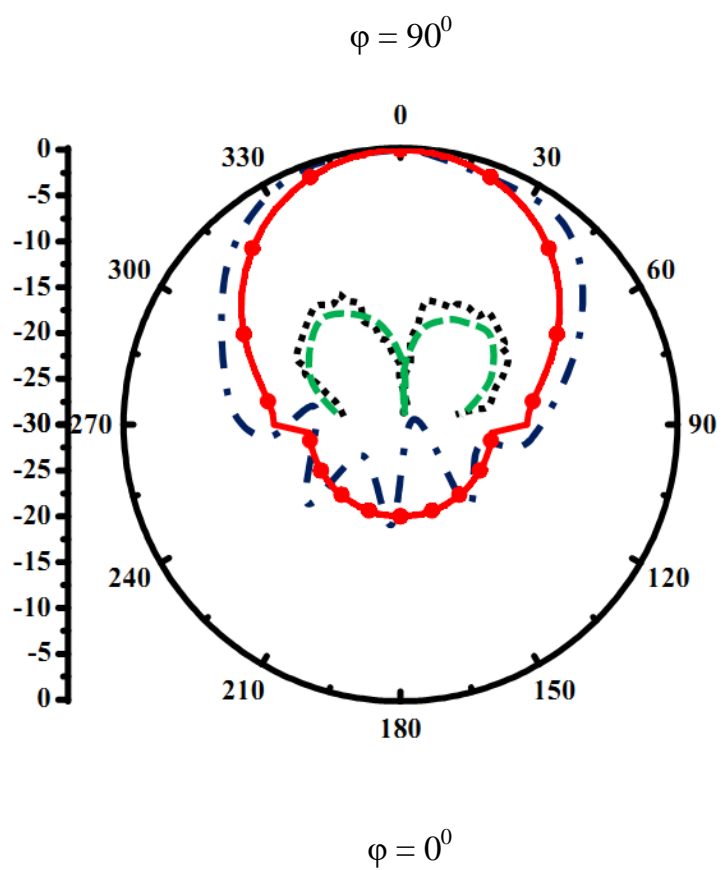

(a)

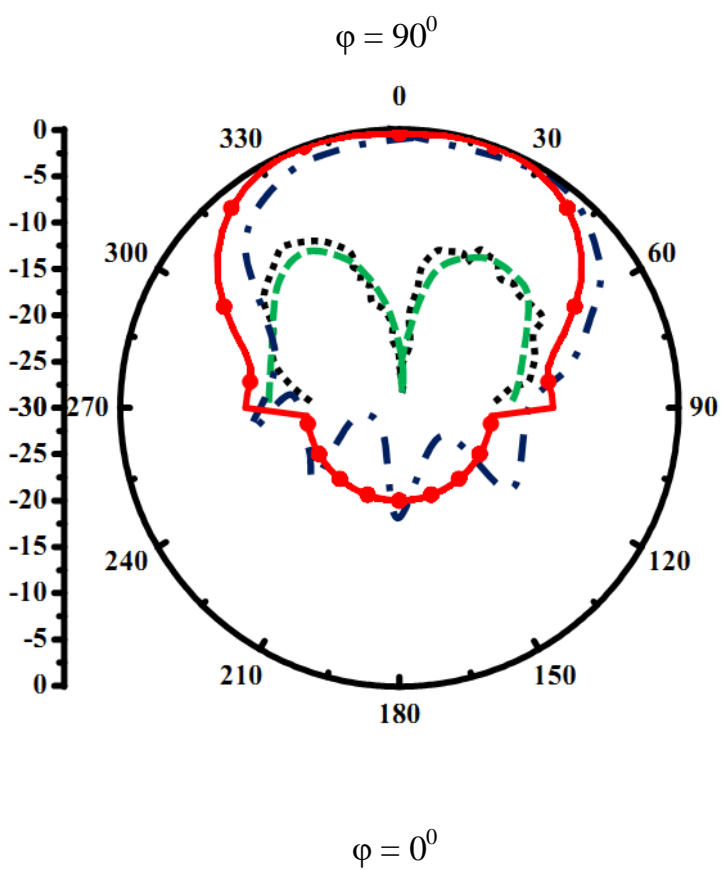

(b)

$\longrightarrow$ Co-polar; --- Cross-polar; simulated $\quad$ - - - - Co-polar ; $\cdots . .$. Cross-polar; measured

Fig. 17. Radiation pattern of DUSPA at (a) $2.80 \mathrm{GHz}$, and (b) $3.09 \mathrm{GHz}$. 

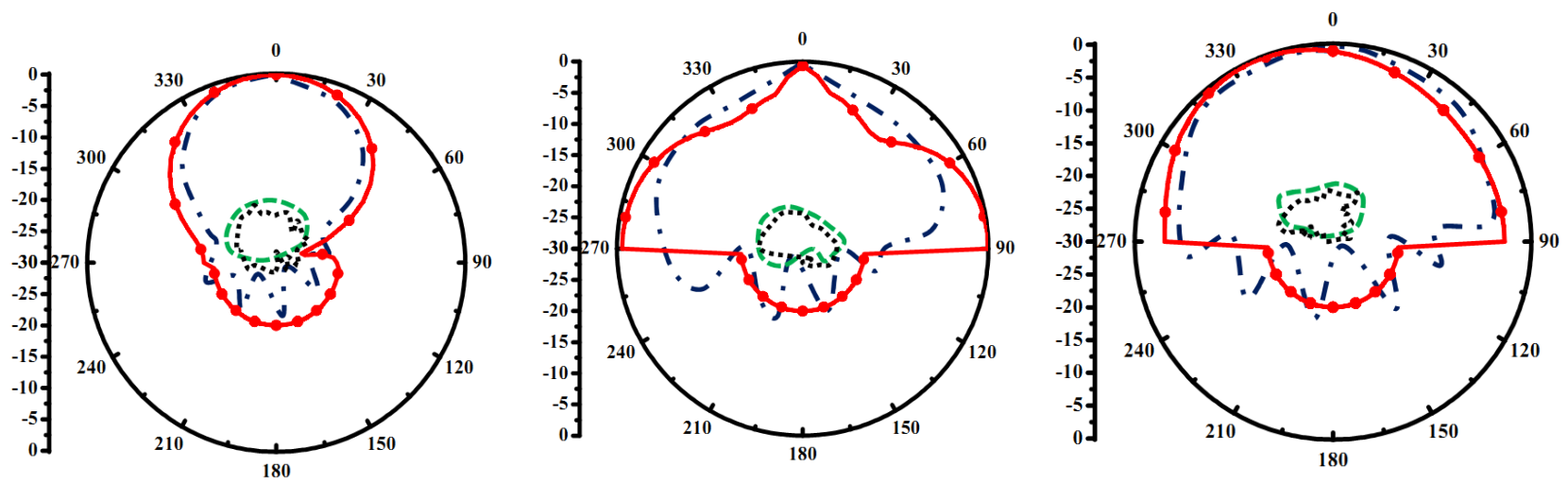

$\varphi=90^{\circ}$

$$
\varphi=90^{\circ}
$$

$\varphi=90^{\circ}$

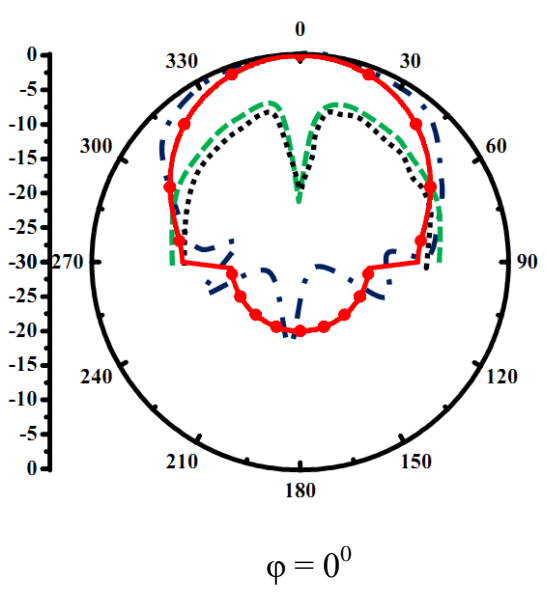

(a)

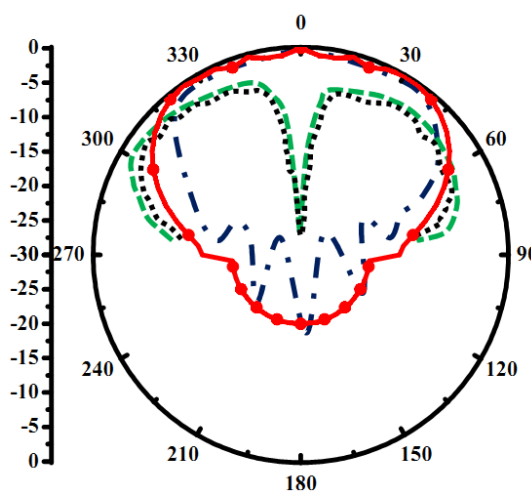

$\varphi=0^{0}$

(b)

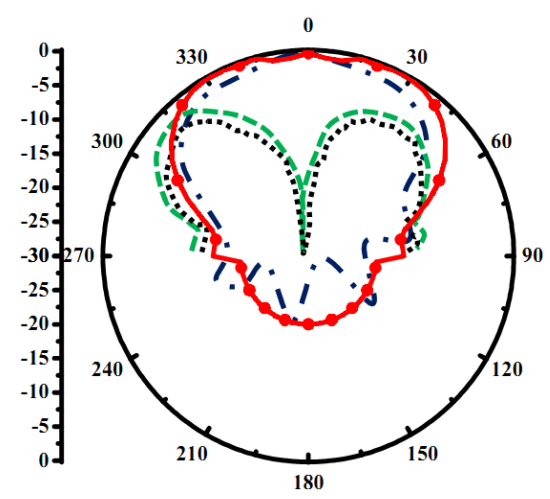

$\varphi=0^{0}$

(c)

$\longrightarrow$ Co-polar; $=--$ Cross-polar ; simulated

- $\cdot$ - $\cdot$ Co-polar ; $\cdots \cdot . \cdot$. Cross-polar; measured

Fig. 18. Radiation pattern of DUSPA with parasitic elements at (a) $3.09 \mathrm{GHz}$, (b) $3.45 \mathrm{GHz}$, and (c) 3.63 $\mathrm{GHz}$

\section{CONCLUSION}

A dual U-slot loaded patch with a modified L-strip feeding technique is presented. The equivalent circuit model is successfully implemented for the calculation of various antenna parameters. The modification in the feeding technique makes the antenna fabrication convenient as compared to proximity coupled L-strip feeding. From this investigation it is inferred that L-probe fed dual U-slot loaded patch increases the bandwidth up to $16.93 \%$. Moreover, when DUSPA is stacked with two parasitic elements, the gap (D) between the two parasitic elements and width $\mathrm{W}_{\mathrm{p}}$ are the key parameters to increase the bandwidth. In this stacked configuration the antenna bandwidth increases up to $25.89 \%$ with maximum gain of $8.46 \mathrm{dBi}$. The dimension of conducting strip can be optimized to further improve the antenna characteristics. Antenna bandwidth can also be controlled with inner and outer U-slot dimensions. This antenna is 
operating in S-band which can be used in weather radar, surface ship radar and other communication satellites.

\section{REFERENCES}

[1] K.L.Wong, Compact and Broadband Microstrip Antennas, New York, Wiley, 2002.

[2] G. Kumar and K. P. Ray, Broadband Microstrip Antennas, Artech House, Norwood, MA, 2003.

[3] B. L. Ooi, “A double- $\pi$ stub proximity feed U-slot patch antenna," IEEE Trans. Antennas Propag., 52, (2004), 2491-2496.

[4] Y. Sung, "Printed Wide-Slot Antenna With a Parasitic Center Patch," IEEE Trans. Antennas Propag., 60 (2012), 1712-1716.

[5] Y. Chen, S. Yang, and Z. Nie, "Bandwidth enhancement method for low profile E-shaped microstrip patch antennas,” IEEE Trans. Antennas Propag., 58, (2010), 2442-2447.

[6] Y. Chen, and C. F. Wang, "Characteristic-mode-based improvement of circularly polarized U-slot and E-shaped patch antennas,” IEEE Antennas Wirel. Propag. Lett., 11 (2012), 1474-1477.

[7] S. Bhardwaj, and R. Y. Samii, “A comparative study of C-shaped, E-shaped, and U-slotted patch antennas," Microw. Opt. Technol. Lett., 54 (2012), 1746-1757.

[8] K. F. Lee, S. L. S. Yang, A. A. Kishk, and K. M. Luk, "The versatile U-slot patch," IEEE Antennas and Propag. Magaz., 52 (2010), 71-88.

[9] Z. Wang, S. Fang, and S. Fu, "Wideband dual-layer patch antenna fed by a modified L-strip," Journal of Microw. Opt. and Electro. Applic., 9, (2010), 89-100.

[10] A. A. Deshmukh, and K. P. Ray, "Broadband proximity-fed modified rectangular microstrip antenna,” IEEE Antenna Propag. Mag., 53 (2011), 1-5.

[11] L. Xu, L. Li, and W. Zhang, "Study and design of broadband bow-tie slot antenna fed with asymmetric CPW,” IEEE Trans. Antenna Propag., 63 (2015), 760-765.

[12] J. A. Ansari, P. Singh, and N. P. Yadav, "Analysis of wideband multilayer patch antenna with two parasitic elements," Microw. Opt. Technol. Lett., 51 (2009), 1397-1401.

[13] N. Safa Nafea, Alyani Ismail, and Raja S. A. Raja Abdullah, "Low side lobe level multilayer antenna for wireless applications," Progress In Electromagnetics Research Letters, 58 (2016), 105111.

[14] W.-L.Chen,G.-M.Wang,andC.X. Zhang, "Bandwidth enhancement of a microstrip-line-fed printed wide-slot antenna with a fractal-shaped slot," IEEE Trans. Antennas Propag., 57 (2009), 21762179 . 
[15] J.-Y. Jan, and L.-C. Tseng, "Small planar monopole antenna with a shorted parasitic inverted-L wire for wireless communications in the 2.4, 5.2, and 5.8-GHz bands," IEEE Trans. Antennas Propag., 52 (2004), 1903-1905.

[16] J. H. Lee, and J. G. Yook, "Improvement of radiation performance of mobile phone antenna using parasitic element," IEEE Trans. Cons. Electron., 56 (2010), 2411-2415.

[17] Tsien-Ming Au, Kin-Fai Tong, and Kwai-Man Luk, "Theoretical and experimental studies of a microstrip antenna with two parasitic patches," Int J RF and Microwave CAE, 8 (1998), 49-55.

[18] K. C. Lin, C. H. Lin, and Y. C. Lin, "Simple printed multiband antenna with novel parasiticelements design for multistandard mobile phone application,” IEEE Trans. Antenna Propag., 61 (2013), 488-491.

[19] I. J. Bahl and P. Bhartia, Microstrip Antenna. Dedham, Artech House, MA 1980.

[20] R. K. Hoffman, Handbook of microstrip integrated circuits, Artech House, Norwood, MA8, 1987.

[21] C. A. Balanis, Antenna Theory: Analysis and Design, $2^{\text {nd }}$ ed. New York: Wiley, 1996.

[22] Shivnarayan and B. R. Vishvakarma, "Analysis of inclined slot loaded patch for dual-band operation,” Microw. Opt. Technol. Lett., 48 (2006), 2436-2441.

[23] A. Gopinath and K.C. Gupta, "Capacitance parameter of discontinuities in microstrip lines," IEEE Trans on Microwave Theory Tech, 26 (1978), 831-836.

[24] N. L. Kester, and R H. Jansen, "The equivalent circuit of the asymmetrical series gap in microstrip and suspended substrate lines,” IEEE Trans on Microwave Theory Tech, 30 (1982), 1273-1279. 